\title{
Research on People's Operation Behavior of Micro-business and Its Influencing Factors
}

\author{
Tingting Tian ${ }^{1, a}$, Weilun Huang ${ }^{1, b, *}$ \\ ${ }^{1}$ School of Finance, Wenzhou Business College, China \\ a995113315@qq.com, bhuangwl@wzbc.edu.cn \\ ${ }^{\star}$ Corresponding author
}

Keywords: Micro-business; People's Operation Behavior; Influencing Factors

\begin{abstract}
The purpose of this paper is to study people's operation behavior of micro-business and its influencing factors by the review of literature and the survey of questionnaire. For there is few literature on people's operation behavior of micro-business, this paper defines people's operation behavior of micro-business as their cost and benefit of micro-business, and then discusses its differences which are influenced by the factors as the cognition of advantages and disadvantages on micro-business and micro-business' platform. The last, this paper analyzes the impact of the operator's gender, age, monthly income and operating micro-business' platform on people's operation behavior of micro-business and its influencing factors. According to the analysis of the questionnaire survey, people's annual average operating cost on the micro-business is less than RMB 1,000 , but their revenue is more than 50 times of their cost. The cognition of advantages and disadvantages on micro-business and micro-business' platform significantly affected the micro-business behavior. The gender and age of respondents would have an obvious impact on people's operation behavior of micro-business, but not all of its influencing factors, and the monthly income and the operating micro-business platform of respondents make no difference.
\end{abstract}

\section{Introduction}

Due to the increase in the number of netizens and the popularity of online micro-business' platforms and social media, micro-businesses based on social media marketing in various countries have developed rapidly. And now micro-business has become the best choice for the Chinese people's second job. According to the literature review, there are still few literatures discussing the operators' cognition of micro-business and the influence of their cognition on their operation behavior of micro-business. Therefore, the purpose of this paper is to study people's operation behavior of micro-business and its influencing factors. According to the literatures, the definition of micro-business in this paper should be a mobile e-commerce model on micro-business' platform or social platform. Its business model is mainly divided into two types, one is based on various micro-business' platform, which named B2C micro-business, such as Wechat official accounts; the other is C2C micro-business in social platform, such as WeChat Moments. Liao and Chen (2016) believe that micro-business is a new type of e-commerce model. With the help of social platforms such as WeChat, QQ and Weibo, it conducts goods and services which transactions in a socialized manner. (Lu and Ji, 2016; Weng, 2015)

According to the literature review, the size and growth rate of micro-business and its operators in many countries are increasing rapidly. For example, iResearch (2017) found that the scale of China's micro-business was RMB 3,607.3 billion in 2016, and estimated RMB 6,83.58 billion (up 89.5\%) in 2017. The number of micro-business operators was estimated 20.2 million in 2017 (the growth rate reached 31.5\%). For example, Karel, et al. (2013) found that the number of employees in micro, small and medium-sized enterprises in the Czech Republic is $60.9 \%$ of the total employment, and their output is $49.5 \%$ of the total output of enterprises; the output of EU micro, small and medium-sized enterprises is $60 \%$ of its GDP. As Parilla (2013) found, the National Small Medium Enterprises Agenda in Philippines is used to promote the development of micro-enterprises, and the number of 
micro-enterprises accounted for 91.9\% of the total number of enterprises. Osotimehin, et al. (2012) found the importance of micro-enterprises in Nigeria and proved that micro-enterprises in Malaysia, Japan, South Korea and other countries have taken most shares of GDP, export value and the number of employees in a country. Kombo, et al. (2011) believed that micro-enterprises are the main driving force for the economic growth of Kenya.

According to the literature, the operator's cognitions of the micro-business should be divided into the advantages and disadvantages of the micro-business and of the micro-business' platform, and they should be the important factors of people's operation behavior of micro-business. For example, the advantage cognitions of micro-business should be divided into the diversification of business, low entry threshold, simple promotion, the freedom to allocate time, economic independence, entrepreneurial experience and self-satisfaction. The disadvantage cognitions of micro-business should be divided into transaction traps, lack of funds, lack of trust, and social tensions. And the advantage cognitions of the micro-business' platform should be divided into zero rent of storage, higher usability, larger social network, and interaction. The disadvantage cognitions of the micro-business' platform should be divided into no promotion mechanism, privacy risk, fraud risk, and quality risk. For example, Zhang and Guo (2015) believe that the advantages of micro-business are the freedom of its operator's time and its diversification; Peng (2014) believes that the disadvantages of micro-business is that its operators would use social platform to quickly and frequently send the promotion information, which causing social tensions. And Yi (2016) believes that the advantages of the micro-business' platform are stronger interactivity, wider range of business and fast communication; Ji and Wang (2015) believe that the disadvantages of the micro-business' platform are fraud problems and the issues of its quality.

This paper also discusses the impact of operator's gender, age, monthly income, and operating micro-business' platform on people's operation behavior of micro-business and its influencing factors. For example, Hammawa and Hashim (2016) found that most of the female entrepreneurs in Nigeria are micro-business operators. In addition to the introduction, the second part of this paper is the literature review of people's operation behavior of micro-business and its influencing factors, the third part is the analysis of questionnaire results, and the fourth part is the conclusion.

\section{Literature Review}

According to the literature, it is known that the people's operation behavior of micro-business should be an important topic of research, but there are still few literatures discussing this topic and its influencing factors. This paper sorts out the existing literature in China and found that the literature about micro-business which marked in the title began in 1957, the most in 2015 (538 articles), and there were 1,870 articles till September 23, 2018. There is a wide range of research fields for existing literature, which mainly focus on the guidance of industry, as well as the research of basic theory and policy, and most discussed by the theoretical and empirical methods. However, there are only two articles in China's existing literature on people's operation behavior of micro-business which marked in the title, and their content focus on its legal supervision. Therefore, the focus of this paper is to explore people's operation behavior of micro-business and its influencing factors, and to supplement the inadequacies of the literature, as well as to provide advice to individuals, enterprises and government related policies.

According to the results of literature review, it is found that the cognitions of advantage and disadvantage on micro-business and micro-business' platform could be used as the influencing factors of people's operation behavior of micro-business. And there is little literature discussing individual variables (gender, age, monthly income and operating micro-business' platform) on people's operation behavior of micro-business and its influencing factors. Therefore, the second focus of this paper is the discussion of the impact of individual variables.

According to relevant literature, this paper defines the variables as follows: 1 . The variables on people's operation behavior of micro-business are set as their annual operating cost and annual revenue. As disclosed by Yu and $\mathrm{Xu}$ (2015), the operating costs of micro-business should include the 
costs of transportation, product procurement and web traffic. As Amit, et al. (2000), Perren (1999) and Watson, et al. (1998) found, the success factors of micro-business are its turnover, growth rate and duration. 2. The variables of the advantage cognitions of micro-business are set that their operators could sell multiple products at the same time; their market-entry barriers are lower, there is no restriction of their location and operating time, their operators could have a second income, their operators could increase the entrepreneurial experience and self-satisfaction by themselves. For example, Shrestha (2004) found that micro-business can improve revenue and the status of female operators. And the income of the poor could be increased by $50-100 \%$ through micro-business. As Rahman and Islam (2003) found micro-businesses can reduce poverty more quickly. Moreover, Zhang (2015) believes the advantages of micro-business are less investment, lower entry threshold, spread wider, and no geographical restrictions.

3. The variables of the disadvantage cognitions of micro-business are set as their trading traps, their difficulties in financing and establishing mutual trust, and others' resentment. For example, Wang, et al. (2015) believed that people's operation behavior of micro-business is easy to cause others to resent. As Osotimehin, et al. (2012) found that insufficient funding is a problem for the development of micro-enterprises in Nigeria. 4. The variables of the advantage cognitions of micro-business' platforms are set as that micro-business do not need a physical store, is simple to operate, has an interactive mechanism, and can expand the circle of friends. For example, Luo (2015) believes that the interactive mechanism of the micro-business' platform can increase marketing speed.

5. The variable of the disadvantage cognitions of micro-business' platform are set that its privacy risks, its fraudulent accidents, its doubts of commodity quantity. For example, Deng, et al. (2017) found there are many issues of privacy and security in China's micro-business platform. 6. Personal variables of respondents are defined as their gender, age, monthly income and operating micro-business’ platform (WeChat, QQ, Weibo, Xiaohongshu, Momo). As Robinson (2008) found most women's savings groups of rural are operating micro-business. Gong (2015) found that micro-business operators in China are mostly women and under 26 years old.

\section{The Analysis of Questionnaire Results}

The questionnaire was conducted on June 15th to June 21st in 2018. There are 525 online questionnaires were completed. Their respondents were all micro-business operators. The statistics of individual variables were: 1 Gender: $30.70 \%$ for men and $69.30 \%$ for women. 2 . Age: The average age of respondents was 24.31 years old (standard deviation was 5.77). 3. Monthly income: The average monthly income of respondents is RMB 2,755.24 (standard deviation is 495.78). 4. Operating Platform (the ratio of usage): WeChat (98.10\%), QQ (63.80\%), Weibo (53.30\%), Xiaohongshu (40.40\%), and Momo (31.60\%).

The descriptive statistics about the variables on people's operation behavior of micro-business are: their average annual operating cost is RMB 780.95 (standard deviation is 668.70), and their average annual revenue is RMB 44,057.16 (standard deviation is 3,8627.66). From the above results, their average annual operating cost of micro-business only takes the purchase cost into account and does not contain the operating cost.

The descriptive statistics of its influencing factors on people's operation behavior of micro-business are: three-quarters of respondents agree that the influencing factors of operation behavior of micro-business are the cognitions of advantage and disadvantage on both the micro-business and their platform. The approval degree of their disadvantage cognition on micro-business is the highest and it is the lowest for their advantage cognition on micro-business. For example, $89.30 \%$ of the respondents agreed with the lack of trust in their disadvantage cognition on micro-business; $85.00 \%$ of the respondents agreed with the larger social networks in their advantage cognition on micro-business' platform; $85.00 \%$ of the respondents agreed with the fraud risk in their disadvantage cognition on micro-business' platform; and $84.80 \%$ of respondents agreed with the freedom to allocate time in their advantage cognition on micro-business. 
In this paper, the variance analysis on people's operation behavior of micro-business and its influencing factors are shown in Table 1. From Table 1, the significant factors of people's operation behavior of micro-business are the advantage and disadvantage cognitions on both the micro-business and its platform. Their significantly positive influencing factors of their operating cost are the advantage cognitions of the micro-business and its platform, and their significantly negative influencing factors are the disadvantage cognitions of the micro-business and its platform. Their significantly negative influencing factor of the micro-business return is the disadvantage cognition on micro-business.

Table 1 The Variance Analysis of People’s Operation Behavior of Micro-Business and its Influencing Factors

\begin{tabular}{|c|c|c|c|}
\hline & \multicolumn{2}{|c|}{$\begin{array}{l}\text { People’s } \quad \text { Operation } \\
\text { Micro-business }\end{array}$} \\
\hline & & Operating Cost & Return \\
\hline \multirow{4}{*}{$\begin{array}{l}\text { Influencing } \\
\text { Factors }\end{array}$} & $\begin{array}{|lll|}\begin{array}{l}\text { The advantage cognition } \\
\text { micro-business }\end{array} & \\
\end{array}$ & $18.61^{* * *}$ & $21.44^{* * *}$ \\
\hline & $\begin{array}{l}\text { The disadvantage cognition on } \\
\text { micro-business }\end{array}$ & $24.98 * * *$ & $7.38 * * *$ \\
\hline & $\begin{array}{l}\text { The advantage cognition on } \\
\text { micro-business' platform }\end{array}$ & $7.91 * * *$ & $15.97 * * *$ \\
\hline & $\begin{array}{l}\text { The disadvantage cognition on } \\
\text { micro-business' platform }\end{array}$ & $16.94 * * *$ & $9.28 * * *$ \\
\hline
\end{tabular}

This paper explores the impact of operator's gender, age, monthly income and operating micro-business' platform on people's operation behavior of micro-business and its influencing factors. The hypothesis testing results of individual variables (their gender and age) on people's operation behavior of micro-business and its influencing factors are listed in Table 2. From Table 2, the gender and age of respondents have a significant impact on the operation behavior of micro-business. For example, the annual operating cost and revenue of female operators are significantly higher than that of males by RMB 700.85 and RMB 50,106.24. If the age of the operator is smaller, the operating cost and revenue of the micro-business are significantly higher.

From Table 2, the gender and age of respondents have significant effects on the factors which would affect people's operation behavior of micro-business. For example, women's advantage and disadvantage recognitions of micro-business are significantly higher than those of men, but their approval degree of the disadvantage cognition of micro-business is significantly lower than that of men. Their Operators in different age have different approval degrees for the advantage and disadvantage cognitions of the micro-business' platform.

According to the statistical results, the monthly income and their operating platform of respondents have no significant impact on people's operation behavior of micro-business and its influencing factors.

From the above discussion, this paper suggests: 1 . Micro-business operators should strengthen the awareness of their financial cost. As the above statistics, the average annual operating cost of micro-business does not reach RMB 1,000. According to the results of respondents' interview, its reason should be their operators only consider the purchase cost, but don't consider the costs of storage, operating (such as hydropower, rent, etc.), labor, transportation, and etc., so their operating cost is substantially underestimated, and their operators should need to strengthen the financial management of cost-benefit. 
Table 2 Hypothesis Testing of Individual Variables (Their Gender and Age) on People’s Operation Behavior of Micro-Business and Its Influencing Factors

\begin{tabular}{|c|c|c|c|c|}
\hline & \multicolumn{2}{|l|}{ Gender } & \multirow{2}{*}{ Age } \\
\hline & & $\mathrm{F}$ & $\mathrm{t}$ & \\
\hline \multirow{2}{*}{$\begin{array}{l}\text { People's Operation } \\
\text { Behavior of } \\
\text { Micro-Business }\end{array}$} & Operating Cost & $110.66^{* * *}$ & $14.00^{* * *}$ & $3.4^{*}$ \\
\hline & Revenue & $581.75^{* * *}$ & $22.95 * * *$ & $8.65^{* * * *}$ \\
\hline \multirow{4}{*}{ Influencing Factors } & $\begin{array}{l}\text { The cognition of advantages on } \\
\text { micro-business }\end{array}$ & $7.99 * *$ & $2.54 *$ & 1.30 \\
\hline & $\begin{array}{l}\text { The cognition of disadvantages } \\
\text { on micro-business }\end{array}$ & $5.79 *$ & -1.40 & 0.12 \\
\hline & $\begin{array}{l}\text { The cognition of advantages on } \\
\text { micro-business' platform }\end{array}$ & 0.01 & 0.20 & $2.72 *$ \\
\hline & $\begin{array}{l}\text { The cognition of disadvantages } \\
\text { on micro-business' platform }\end{array}$ & 0.60 & $-3.99 * * *$ & $2.68 *$ \\
\hline
\end{tabular}

2. Due to the high rate of micro-business returns, there would be a law in 2019 which regulated people's operation behavior of micro-business in China, so micro-business operators should formulate response strategies as soon as possible. According to the statistical results, the yield of micro-business is as high as 5,641.48\%. Although China's micro-businesses currently ought to pay taxes, there should be no operator to make this declaration. Therefore, Article 11 of the Electronic Commerce Law of the People's Republic of China promulgated by the Chinese government on August 31, 2018 (officially implement it on January 1, 2019) stipulates that micro-business operators should pay taxes.

3. The operators of micro-business should pay close attention to the adjustment of regulations, social and economic environment. The advantages and disadvantages of micro-business would depend on regulations, social and economic environment, For example, in Articles 27 and 32 of the Law of the People's Republic of China on Electronic Commerce, micro-business operators need to apply for business licenses, as well as provide quality assurance, consumer rights protection, and privacy rights. This has heightened the barriers to entry, but it also reduces its disadvantages such as privacy risk, fraud risk and quality risk.

4. The support policy of micro-business should consider their operators' gender and age, for people's operation behavior of micro-business and its influencing factors will be affected by the gender and age of their operators.

5. People's operating micro-business' platforms in China don't make any difference on their operation behavior today, so the business owners of such platforms should shape their brand image and make market-divided marketing strategies.

\section{Conclusion}

With the marked increase of netizens and the popularity of social platforms in China, and the scope and scale of micro-businesses continue to increase, micro-business has become the best choice for the Chinese people's second job. Therefore, people's operation behavior of micro-business has become an important topic for industry, government and scholars. However, there are still few relevant literatures today. The purpose of this paper is to explore people's operation behavior of micro-business and its influencing factors, and to analyze the influence of gender, age, monthly income and micro-business' platform.

According to the literature review and the statistical results of the questionnaire, the results are: 1 . People's operation behavior of micro-business can be divided into the micro-business cost and revenue, and their revenue in China is more than 50 times of the cost, so the micro-business is supposed be an industry that people in China would actively operate. 2. The advantage and disadvantage cognitions on micro-business and its platform have a significant impact on people's operation behavior of micro-business. Therefore, the policies for supporting micro-business should 
concentrate on the education and training about the influencing factors of people's operation behavior of micro-business. 3. The gender and age of micro-business operators would make different on micro-business practices, so the related industry, government, and scholars should conduct research or market-divided marketing strategies on related topics.

The further research of their influencing factors could consider the degree of market competition and the laws and regulations on micro-business. For example, Talebi and Ghavamipour (2012) found that the degree of market competition would affect the performance of micro-business. Moreover, Patel and Chavda (2013) emphasize the impact of law on the performance of micro-business.

\section{References}

[1] Weng Chuzhe, Foresee the Future Development of Micro-business Based on Its Current Development Status, Market Modernization, 2015(03):79-80.

[2] Liao Wenfang, Chen Fen, Analysis of the Status Quo and Development Trend of Chinese Micro-business, Contemporary Economics, 2016(07):46-48.

[3] Research Report of the Micro-business Industry in China in 2017, iResearch, 2017.

[4] Karel, S., Adam, P., and Radomir, P., Strategic Planning and Business Performance of Micro, Small and Medium-Sized Enterprises, Journal of Competitiveness, Vol. 5, Issue 4, pp. 57-72, December 2013 ISSN 1804-171X (Print), ISSN 1804-1728 (On-line), DOI: 10.7441/joc.2013.04.04.

[5] Parilla, E. S., Level of Management Practices of Micro and Small Businesses in Ilocos Norte, International Journal of Academic Research in Business and Social Sciences, July 2013, Vol. 3, No. 7 ISSN:2222-6990 , DOI : $10.6007 /$ IJARBSS/v3-i7/67 , URL:http://dx.doi.org/10.6007/IJARBSS/v3-i7/67.

[6] Osotimehin, K. O., Jegede, C. A, Akinlabi, B. H., An Evaluation of the Challenges and Prospects of Micro and Small Scale Enterprises Development in Nigeria, American International Journal of Contemporary Research, Vol. 2 No. 4; April 2012, 174-185. www.aijcrnet.com.

[7] Kombo, A. et al, An Evaluation of the Impact of Risk management Strategies on Micro-Finance Institutions' Financial Sustainability: A case of Selected Micro finance institutions in Kisii Municipality, Kenya, 2011.

[8] Zhang Yang, Guo Jinli, Advantages and Disadvantages of Micro-business Marketing Compared with Taobao E-commerce, Electronic Science \& Technology Review, 2015(08):27-28+72.

[9] Peng Yubing, On the Definition and Status Quo of Micro-business, Fortune Time, 2014(12):29.

[10]Yi Fenghua, Analysis of Weibo Marketing Strategies for Enterprises and Individuals, Journal of Hubei University of Economics (Humanities and Social Sciences), 2016,13(11):63-64+67.

[11]Ji Miao, Wang Mingyu, Industry Analysis Report of Micro-business, China Business \& Trade, 2015(Z1):55-57. 